\title{
CLINICAL OUTCOME OF WEARING IMPLANT RETAINED OVER DENTURE IN PATIENTS WITH ATROPHIC ANTERIOR MAXILLA RECONSTRUCTED BY SUB NASAL LIFTING (CLINICAL STUDY)
}

\author{
Yassmin A. Tahamawy ${ }^{l} B D S$, Faten S. Abbas ${ }^{2} P h D$, Nevien S. Abdallah ${ }^{3} P h D$ \\ ABSTRACT
}

INTRODUCTION: Maxillary implant overdenture has improved the quality of life for edentulous patients especially patients with atrophic maxilla. Sub-nasal lifting was introduced to solve the problem of severely atrophic anterior edentulous maxilla to allow insertion of dental implants. The type of attachment may influence the retention and stability of the prosthesis and thus, masticatory efficiency. Especially locator attachment is used with great success for improvement of implant-assisted over denture

OBJECTIVES:To evaluate clinically and radiographically the effect of wearing implant- retained over denture in patients with atrophic anterior maxilla which was reconstructed by nasal lifting. Patient satisfaction was also evaluated.

MATERIALS AND METHODS: This clinical trial was conducted on seven patients with edentulous atrophic anterior maxilla rehabilitated by Sub-Nasal Lifting, restored with bilateral two implants and grafted with Platelet-Rich Fibrin. For each patient an implant- retained over denture with locator attachments was constructed. Patient assessment was done using different three method including clinical, radiographic evaluation and patient satisfaction at three intervals; at time of over denture insertion, 3 months and 6 months of denture use.

RESULTS: All patients showed increased bone density around dental implants with slight decrease in marginal bone height, no mobility of each implant was detected.All patient showed increased well satisfaction throughout the follow up periods.

CONCLUSIONS Two implant-assisted maxillary over denture is an acceptable treatment for patients with atrophic anterior maxilla and it showed increased patient satisfaction and favorable clinical and radiographic findings.

KEYWORDS: Maxillary over denture, two implants, nasal lifting, patient satisfaction, peri-implant tissue.

1. Instructor at Department of Removable Prosthodontic, faculty of Dentistry, Alexandria University, Alexandria, Egypt.

2. Professor of Prosthodontic, faculty of Dentistry, Alexandria University, Alexandria, Egypt.

3. Professor of oral\&maxilla facial surgery, faculty of Dentistry, Alexandria University, Alexandria, Egypt.

\section{INTRODUCTION}

Edentulism is associated with several deleterious effects on oral health including degenerative changes of the alveolar bone, reduction of height and width of available bone for dental prosthesis (1). In addition to its negative impact on oral health, edentulism has also detrimental effects on general health (2).

Following tooth loss, lack of alveolar bone stimulation leads to decrease in trabeculae and bone density in the area with loss in external width then height of the bone volume $(3,4)$. Reduction of anterior maxillary bone dimension, both width and height, can reach up to $70 \%$, especially if multiple extractions were performed and followed by alveoloplasty before delivery of a maxillary denture (5).

Treatments for edentulous maxilla patients specifically with severe degree of resorption can be performed through several techniques-bone augmentation or grafting; using angled implants in parasinus region; placing implant in the pterygoid apophysis; using short and wide implants; or using zygomatic implants (6).

Bone augmentation has been regarded as the gold standard procedure to treat atrophic maxilla. Le Fort I osteotomy with interpositional grafting and distraction osteogenesis are among augmentation procedures performed to restore the lost bone (7).

Restorative implant solutions for the edentulous maxilla include: removable overdenture therapy and fixed restoration (8). Zygomatic, small diameter implant and tilted implants all are used to restore maxilla when insufficient bone height was available $(9,10)$.

Reports of treatments involving two- implants maxillary over dentures with partial palatal coverage are limited but not entirely unfavorable (11). Providing only two implants in the maxilla does not compromise the longevity of the prostheses or patient satisfaction compared with 4-implant overdentures (12).

The newly developed locator attachment system has become widely applied. Recently, the locator attachment system being characterized by a low profile design, ease of seating in the oral cavity by the patient, self-locating feature to fit non-parallel implants up to $40^{\circ}$ divergence (13). Other studies have reported that locator attachment system possessed the highest retentive force and maintained that force up to $30^{\circ}$ tilting when compared to ball system (14). Placement of dental implants in a severely resorbed anterior maxillary alveolar ridge is limited by the fact that implants may penetrate the nasal cavity. Recently, Mazor (15), investigated the use of bovine bone material for augmentation of the nasal floor and simultaneous insertion of dental implants during the same procedure. No implant failure was reported in this study.

Also, El-Ghareeb (16) reconstructed atrophic maxilla cases by performing nasal floor augmentation. The implant survival rate in his study was $100 \%$. He concluded that "The use of osteoconductive bone substitutes for nasal floor augmentation, as shown in this small case series, is a 
reliable method for reconstruction of the anterior atrophic maxilla for implant-supported over dentures" .

Finally, a straight forward, minimal invasive and cost effective treatment option for atrophic edentulous anterior maxilla could be the placement of two implants at the canine area bilaterally following nasal lifting. Supporting this treatment approach using clinical, radiographic and patient satisfaction questionnaire is our aim.

\section{MATERIALS AND METHODS}

The clinical part of the study was performed after the approval of research ethics committee, Faculty of Dentistry, Alexandria University. Official consent was obtained from the patients. The patients received both oral and written information about the study protocol and signed an informed consent to participate in the study.

\section{Patient rehabilitation}

This study was conducted on seven completely edentulous patients having atrophic edentulous anterior maxilla and who found difficulty to be restored by conventional complete denture or insertion of implant at anterior atrophic maxilla. Those patients were previously rehabilitiezed using sub nasal lifting, and restored with bilateral two implants at canine area and grafted with platelet-rich fibrin (PRF). For each patient an implant retained over denture with locator attachment was constructed.

Prior to sub nasal surgical phase, a set of complete maxillary and mandibular dentures was fabricated for every patient according to standardized conventional technique.

Nasal lifting procedure with two implant placement (Dentium Co.Ltd, Korea) and platelet rich fibrin (PRF) grafting at the atrophic anterior maxillary edentulous area was done at the department of oral \&maxillo facial surgery. The implants were inserted at the canine area bilaterally. The maxillary complete denture was relined with soft liner for the following six months (osseointegration phase).

Following the six months of osseointegration phase, new conventional complete denture set was constructed for each patient. The implants were uncovered by small crestal incisions at the location of the implants (Figure 1);
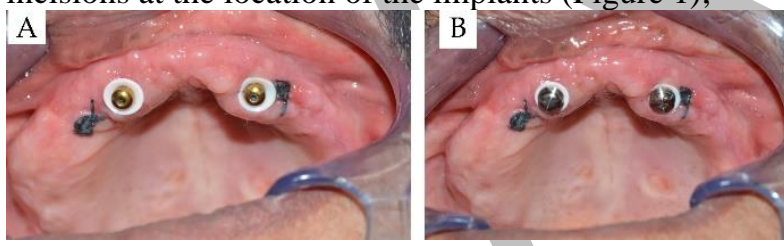

Figure (1): Showing crestal incision at the location of implant.

the exact location was determined using the previously used surgical template. The cover screws were removed and the healing caps were placed and left for one week allowing the gingiva to heal.

Healing abutments have been removed and abutments with Locator Positioner attachment and $2 \mathrm{~mm}$ collar height were fixed in place (Figure 2).
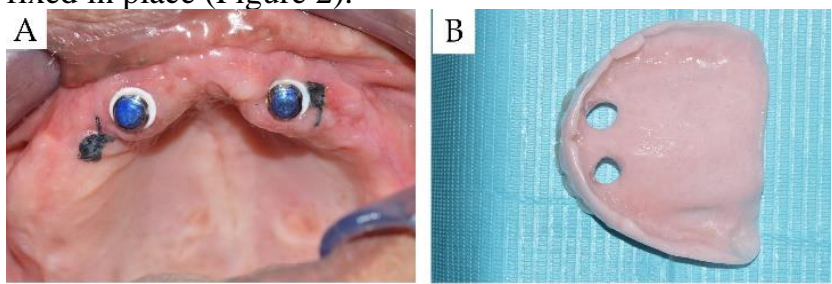

Figure(2):Showing Abutments with Locator (Positioner) attachment
The locator Positioner abutment (L13D102811, DentiumCo.Ltd, Korea) selected for this stud0y was low profile $(2 \mathrm{~mm})$ collar height with $3.5 \mathrm{~mm}$ diameter with a socket set(Positioner socket set FSMHS, DentiumCo.Ltd, Korea.)

White block-out spacers were placed over the head of each Locator abutment (Figure 3(a)). The spacers were used to block out the area surrounding the abutment, a metal socket with white processing cap was inserted into each Positioner implant abutment, leaving the white block-out spacer beneath it (Figure 3 (b)).
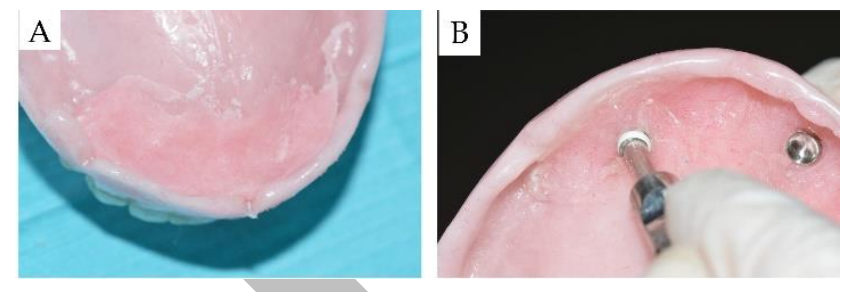

Figure (3):Showing a) White block-out spacers were placed. b) A metal socket with (white processing cap)

The maxillary denture was seated into the patient's mouth to determine the locations of the metal housings relative to the tissue-bearing surface of the prosthesis by marking the metal housings with indelible pencil (Figure 4 (a)). Recesses were prepared in the fitting surface of the maxillary denture to accommodate the protruding Positioner metal socket. Small relief holes were drilled through the top of the recesses palatally, to allow excess acrylic to escape (Figure 4 (b)).

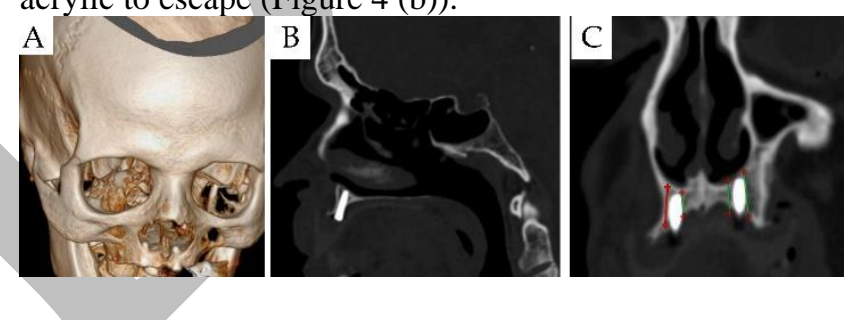

The spaces provided in the fitting surface of the maxillary denture over the metal housings were wetted with autopolymerized acrylic resin monomer. A mix of autopolymerized acrylic resin "pick-up material" was prepared, and the spaces were filled using a plastic filling instrument (Figure 5(a)). The denture was inserted into position in the oral cavity. The patient gently guided into centric occlusion to maintain proper relationship with the opposing arch, direct pick up (17).

The locator core tool (Positioner Core Tool XPCT, DentiumCo.Ltd, Korea)was used for the procedure of removing the white processing cap from the socket and replacing it with the final nylon cap replacement, Ivory colored Figure 5 (b)). Then the occlusion was readjusted intra-orally. The nylon caps were changed from ivory (least retention) to orange (medium retention) to blue (highest retention) within one month.

\section{Patient evaluation}

\section{Radiographic evaluation}

Radiographic evaluation of the bone around the implants for this study included:

Assessment of peri-implant marginal bone height changes. Assessment of peri-implant bone density

Computerized tomography was used to evaluate the periimplant tissue according to bone density as well as ridge height values using computer softwareradiant DICOM 
viewer (RadiAnt DICOM viewer, Medixant, Poland) the assessment was done at time of implant assisted over denture insertion and after 6 months of over denture use(Figure (a-c)).

Patient satisfaction evaluation

Patient satisfaction was evaluated according to different parameters at time of over denture insertion, 3 months and 6 months after over denture use (18).

\section{Clinical evaluation}

\section{Mobility}

Mobility of the implants was assessed by placing each abutment between the ends of two blunt instruments and applying alternate pressure. A two point scale was used, namely mobile or non-mobile as recommended by Smith and Zarb (19).

\section{Statistical analysis:}

Data were fed to the computer and analyzed using IBM SPSS software package version 20.0. (Armonk, NY: IBM Corp) Qualitative data were described using number and percent. The Kolmogorov-Smirnov test was used to verify the normality of distribution Quantitative data were described using range (minimum and maximum), mean, standard deviation and median. Significance of the obtained results was judged at the $5 \%$ level.

The used tests were

McNemar-Bowker and Marginal Homogeneity Test

Used to analyse the significance between the different stages

Paired t-test

For normally quantitative variables, to compare between two periods

\section{RESULTS}

Radiographic evaluation:

Assessment of peri-implant marginal bone height changes: (Table 1) showed slight decrease in the mean marginal bone height throughout the period of follow up, but with nonsignificant statistical values, with $(\mathrm{P}=0.083)$ at right side, $(\mathrm{P}=0.127)$ at left side and $(\mathrm{P}=0.059)$ at both of them.

Assessment of peri-implant bone density: (Table 2 ) showed a statistical increase in the mean peri-implant bone density (HU) throughout the follow-up period especially at the right side with $(\mathrm{P}=0.049)$ which was statistically significant increase and also the same statistical significant increase recorded at the average of both right and left implants with $(\mathrm{P}=0.028)$.

Patient satisfaction evaluation

Table3 showeda gradual increase in patient satisfaction parameters throughout the different periods of follow up especially at the end of 6 months period

Regarding the chewing efficiency: $71.4 \%$ of the patients presented well satisfaction with their stable dentures till the end of 6 months follow up period and $28.6 \%$ were satisfied. At the same time, tasting parameter was improved with well satisfaction for $42.9 \%$ and satisfaction of $57.1 \%$ of the patients.

For Speech parameter, also $71.4 \%$ of the patient showed well improvement at the end of 6 months follow up period. As regard to Pain, no one of the patients showed satisfaction at time of insertion, but at the intervals of 3-months and 6months, $57.1 \%$ of the patients reported good satisfaction without any pain complain.

-It was found that $71.4 \%$ of the patients were satisfied with their esthetics and $28.6 \%$ were well satisfied.
Denture retention and stability parameters, showed that all the patients $(100 \%)$ reported significant improvement specially at the end of 6 months follow up period.

As regard to comfort no one of the patients showed any discomfort with their dentures at both the three and six months follow up periods.

Clinical evaluation

Mobility

None of the implants showed any signs of mobility throughout the evaluation period, so mobility scores were zero.

Table (1): Distribution of the studied cases according to marginal bone height.

\begin{tabular}{||c|c|c|c||}
\hline Bone height & $\begin{array}{c}\text { At time of } \\
\text { over denture } \\
\text { insertion }\end{array}$ & $\begin{array}{c}\text { 6 months of over } \\
\text { denture use }\end{array}$ & P \\
\hline Right implant & $13.28-13.32$ & $13.20-13.32$ & \\
Min. - Max. & $13.31 \pm 0.02$ & $13.27 \pm 0.06$ & 0.083 \\
Mean \pm SD. & 13.32 & 13.30 & \\
Median & & $13.25-13.35$ & \\
\hline Left implant & $13.30-13.35$ & $13.30 \pm 0.04$ & 0.127 \\
Min. - Max. & $13.32 \pm 0.01$ & 13.30 & \\
Mean \pm SD. & 13.33 & $13.23-13.33$ & \\
Median & & $13.28 \pm 0.04$ & 0.059 \\
\hline Average (RT, LT) & $13.30-13.33$ & 13.30 & \\
Min. - Max. & $13.32 \pm 0.01$ & 13.32 & \\
Mean \pm SD. & Median & \multicolumn{2}{|l}{} \\
\hline
\end{tabular}

$\mathrm{p}$ : $\mathrm{p}$ value for Paired t-test for comparing betweenPreoperative and Post-operative.

Table (2): Distribution of the studied cases according to bone density.

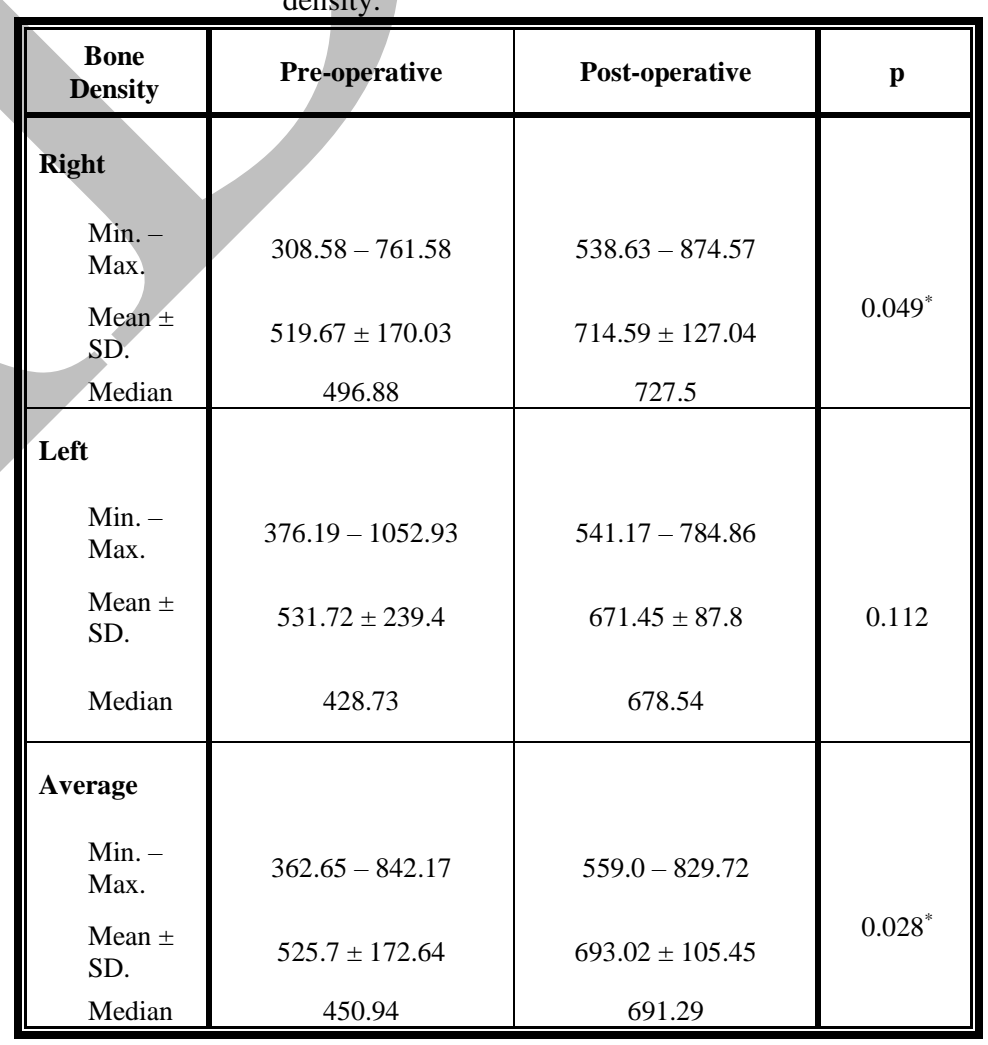

$\mathrm{p}$ : $\mathrm{p}$ value for Paired t-test for comparing betweenPreoperative and Post-operative

*: Statistically significant at $\mathrm{p} \leq 0.05$ 
Table (3):Distribution of the studied cases according to different parameters of patient satisfaction.

\begin{tabular}{|c|c|c|c|c|c|c|}
\hline & \multirow{2}{*}{\multicolumn{2}{|c|}{$\begin{array}{c}\text { At time of } \\
\text { denture } \\
\text { insertion }\end{array}$}} & \multicolumn{4}{|c|}{ Post-operative } \\
\hline & & & \multicolumn{2}{|c|}{3 months } & \multicolumn{2}{|c|}{6 months } \\
\hline & No. & $\%$ & No. & $\%$ & No. & $\%$ \\
\hline Chewing & & & & & & \\
\hline Dissatisfied & 1 & 14.3 & 0 & 0.0 & 0 & 0.0 \\
\hline Satisfied & 3 & 42.9 & 2 & 28.6 & 2 & 28.6 \\
\hline $\begin{array}{l}\text { Well } \\
\text { satisfied }\end{array}$ & 3 & 42.9 & 5 & 71.4 & 5 & 71.4 \\
\hline Sig. bet. periods & \multicolumn{6}{|c|}{$\mathrm{p}_{1}=0.083, \mathrm{p}_{2}=0.083, \mathrm{p}_{3}=1.000$} \\
\hline \multicolumn{7}{|l|}{ Tasting } \\
\hline Satisfied & 5 & 71.4 & 4 & 57.1 & 4 & 57.1 \\
\hline $\begin{array}{l}\text { Well } \\
\text { satisfied }\end{array}$ & 2 & 28.6 & 3 & 42.9 & 3 & 42.9 \\
\hline Sig. bet. periods & \multicolumn{6}{|c|}{$\mathrm{p}_{1}=1.000, \mathrm{p}_{2}=1.000, \mathrm{p}_{3}=1.000$} \\
\hline \multicolumn{7}{|l|}{ Speech } \\
\hline Satisfied & 5 & 71.4 & 3 & 42.9 & 2 & 28.6 \\
\hline $\begin{array}{l}\text { Well } \\
\text { satisfied }\end{array}$ & 2 & 28.6 & 4 & 57.1 & 5 & 71.4 \\
\hline Sig. bet. periods & \multicolumn{6}{|c|}{$\mathrm{p}_{1}=0.500, \mathrm{p}_{2}=0.250, \mathrm{p}_{3}=1.000$} \\
\hline \multicolumn{7}{|l|}{ Pain } \\
\hline Dissatisfied & 2 & 28.6 & 0 & 0.0 & & 0.0 \\
\hline Satisfied & 5 & 71.4 & 3 & 42.9 & 3 & 42.9 \\
\hline $\begin{array}{l}\text { Well } \\
\text { satisfied }\end{array}$ & 0 & 0.0 & 4 & 57.1 & 4 & 57.1 \\
\hline Sig. bet. periods & \multicolumn{6}{|c|}{$\mathrm{p}_{1}=0.014^{*}, \mathrm{p}_{2}=0.034^{*}, \mathrm{p}_{3}=1.000$} \\
\hline \multicolumn{7}{|l|}{ Esthetics } \\
\hline Dissatisfied & 1 & 14.3 & 0 & 0.0 & 0 & 0.0 \\
\hline Satisfied & 4 & 57.1 & 5 & 71.4 & 5 & 71.4 \\
\hline $\begin{array}{l}\text { Well } \\
\text { satisfied }\end{array}$ & 2 & 28.6 & 2 & 28.6 & 2 & 28.6 \\
\hline Sig. bet. periods & \multicolumn{6}{|c|}{$\mathrm{p}_{1}=0.317, \mathrm{p}_{2}=0.317, \mathrm{p}_{3}=1.000$} \\
\hline \multicolumn{7}{|l|}{ Retention } \\
\hline Satisfied & 6 & 85.7 & 1 & 14.3 & 0 & 0.0 \\
\hline $\begin{array}{l}\text { Well } \\
\text { satisfied }\end{array}$ & 1 & 14.3 & 6 & 85.7 & 7 & 100.0 \\
\hline Sig. bet. periods & \multicolumn{6}{|c|}{$\mathrm{p}_{1}=0.063, \mathrm{p}_{2}=0.031^{*}, \mathrm{p}_{3}=1.000$} \\
\hline \multicolumn{7}{|l|}{ Comfort } \\
\hline Dissatisfied & 2 & 28.6 & 0 & & 0 & 0.0 \\
\hline Satisfied & 5 & 71.4 & 3 & 42.9 & 3 & 42.9 \\
\hline $\begin{array}{l}\text { Well } \\
\text { satisfied }\end{array}$ & 0 & 0.0 & 4 & 57.1 & 4 & 57.1 \\
\hline Sig. bet. periods & \multicolumn{6}{|c|}{$\mathrm{p}_{1}=0.014^{*}, \mathrm{p}_{2}=0.034^{*}, \mathrm{p}_{3}=1.000$} \\
\hline \multicolumn{7}{|l|}{ Stability } \\
\hline Satisfied & 3 & 42.9 & 1 & 14.3 & 0 & 0.0 \\
\hline $\begin{array}{l}\text { Well } \\
\text { satisfied }\end{array}$ & 4 & 57.1 & 6 & 85.7 & 7 & 100.0 \\
\hline Sig. bet. periods & \multicolumn{6}{|c|}{$\mathrm{p}_{1}=0.500, \mathrm{p}_{2}=0.250, \mathrm{p}_{3}=1.000$} \\
\hline
\end{tabular}

Sig. bet. Periodswas done by using Marginal Homogeneity Testor McNemar test.

$\mathrm{p}_{1}$ : $\mathrm{p}$ value for comparing between at time of denture insertion and after 3 months

$\mathrm{p}_{2}: \mathrm{p}$ value for comparing between at time of denture insertion and after 6 months

$\mathrm{p}_{3}: \mathrm{p}$ value for comparing between after 3 months and after 6 months

*: Statistically significant at $\mathrm{p} \leq 0.05$

\section{DISCUSSION}

The prosthodontic literatures regarding maxillary implant assisted over denture lacks established scientific evidence that clinicians may use to guide clinical procedures and concepts.

If a larger number of implants is not associated with improved clinical results and there are economic and surgical benefits for patients with the use of a smaller number of implants, maxillary over denture treatment with two implants may warrant further consideration. And this was the hypothesis of our study.

In this study seven patients were selected with atrophic anterior maxilla which was contraindicated for implant insertion or over denture construction. All patients were previously rehabilitated by mucosal nasal lifting technique and grafting with platelet rich fibrin (PRF), then followed by two implants insertion bilaterally at the canine area.

Nasal lifting was used because it successfully creates favorable space for implant placement at the anterior maxilla (20). Platelet rich fibrin (PRF) was also selected as a grafting material because of its ability to seal biological tissue, accelerate wound healing and support osseous regeneration (21).

Locator attachment was applied in this study because of its low profile in addition to its innovative ability to pivot, that increase resiliency and tolerance for high mastication forces (22).

The locator attachments were connected to the maxillary denture directly intra-orally under maximal biting force during polymerization of the acrylic resin to insure passivity during seating and function of the over denture after abutment connection. This used intra-oral direct technique was simple, quick, and eliminated the dimensional changes and misfit that might be occurred if extra-oral indirect technique has been used (23).

In this study a new version of multi-slices high speed three dimensional CT accompanied with (DICOM viewer) software was used It provides a high resolution image with well-defined image layer preserving soft tissue details, multi-planar 3-dimensional views, it allows simultaneous study of multiple implant sites. Furthermore, bone density can be measured on CT data, and this is important in assessing bone quality (24).

Regarding the marginal bone level changes, there was a slight insignificant decrease in the marginal bone level throughout this study.

The screw design of the implants which created more intimate contact with bone during placement might be a cause for increased percentage of bone attachment to the implant and reducing the peri-implant bone loss as reported by Sykaras N, et al (25). Moreover using resilient Locator attachment may lead to decrease in the magnitude of forces reaching to the implant abutments and hence to the crestal supporting bone (26).

Measurements of bone density around the endosteal implants where the mechanical distribution of stress occurs primarily, showed a significant increase in peri-implant bone density, throughout the whole follow up period of 6 months.

This increase in bone density can be attributed to the explanation that in function, the denture base permitted vertical movements by the virtue of the resilient attachment system, thus delivering physiological normal stimulation of the peri-implant bone. This concept of the mechanical 
stimulation of bone around implants was evaluated and confirmed by a study by Rubin CT and Mcleod KJ (27).

Moreover, the self-locating design of the Locator allows patients to easily seat and remove their dentures without exertion of excessive force (passive fitting and removal of the prosthesis) which allow for more residual bone preservation with increasing peri-implant bone density (28). Improved patient satisfaction was found throughout this study following using the maxillary implant-assisted dentures regarding speech, comfort, esthetics, stability, chewing ability and retention throughout evaluation periods.

Patient satisfaction was increased gradually as a certain time of adaptation was needed with new dentures. Also with increased retention with implant which might contribute to increased ability to speak well and chew thus increasing general comfort of the patient this explanation can be related to a study Konstrom et al (29).

Retention and stability were increased which might be due to the use of locator attachment system. As recommended by Kapur et al (30), who found that stability improved significantly for implant-supported dentures compared with conventional dentures.

Reports of treatments involving two - implant maxillary over dentures with partial palatal coverage are limited but not entirely unfavorable. Providing only two implants in the maxilla does not compromise the longevity of the prostheses or patient satisfaction compared with 4-implant over denture $(11,31,32)$.

Two implant over denture (OD) in the maxilla were also tested in a study by Bergendal and Enquist (12).they reported that cumulative implant survival rates after 7 years were $75 \%$ in the maxillae. Although the survival rate of maxillary implants was relatively low, there was no difference in the implant survival between the attachment systems. Only two implants in the anterior region of the maxilla were used in all patients.

It was clear from the previous discussion that the use of two implants at the anterior atrophic maxilla rehabilitated by mucosal nasal lifting and wearing implant assisted over denture showed successful parameters and accepted by the patients.

\section{CONCLUSION}

1) Radiographically, peri-implant tissue showed slight insignificant decrease in marginal bone height but significantly increased bone density under overdenture loading was recorded throughout the whole follow up periods.

2) The present results reported that maxillary over dentures retained by two implants provided significant improvement in oral and health-related qualities of life (patient satisfaction).

3) No signs of implant mobility were detected with the use of two implant assisted over denture.

\section{CONFLICT OF INTEREST}

The authors declare that they have no conflicts of interest.

\section{REFERENCES}

1) Tallgren A. The continuing reduction of the residual alveolar ridges in complete denture wearers: a mixed- longitudinal study covering 25 years. J Prosthet Dent. 2003;89:427-35.

2) Emami E, de Souza RF, Kabawat M, Feine JS. The impact of edentulism on oral and general health. Int $\mathbf{J}$ Dent. 2013;2013:498-305.

3) Cawood JI, Stoelinga PJ, Blackburn TK. The evolution of preimplant surgery from preprosthetic surgery. Int J Oral Maxillofac Surg. 2007;36:377-85.

4) Nkenke E, HahnM, Lell M, Wiltfang J, Schultze-Mosgau S, Stech B, et al. Anatomic site evaluation of the zygomatic bone for dental implant placement. Clin Oral Implants Res. 2003;14:72-9.

5) Berg H, Carlsson GE, Helkimo M. Changes in shape of posterior parts of upper jaws after extraction of teeth and prosthetic treatment. J Prosthet Dent. 1975;34:262-8.

6) Davo R, Malevez C, Rojas J, Rodriguez J, Regolf J. Clinical outcome of 42 patients treated with 81 immediately loaded zygomatic implants: a 12- to 42-month retrospective study. Eur J Oral Implantol. 2008;9(Suppl 1):141-50.

7) Kondell PA, Nordenram A, Moberg LE, Eliasson S, Nyberg B. Reconstruction of the resorbed edentulous maxilla using autogenous rib grafts and osseointegrated implants. Clin Oral Implants Res. 1996;7:286-90.

8) Henry PJ. Future therapeutic directions for management of the edentulous predicament. J Prosthet Dent. 1998;79:1006.

9) Ferrara ED, Stella JP. Restoration of the edentulous maxilla: the case for the zygomatic implants. J Oral Maxillofac Surg. 2004;62:1418-22.

10) Malo P, Nobre Mde A, Petersson U, Wigren S. A pilot study of complete edentulous rehabilitation with immediate function using a new implant design: case series. Clin Implant Dent Relat Res. 2006;8:223-32.

11) Klemetti E. Is there a certain number of implants needed to retain an overdenture? J Oral Rehabil. 2008;35 (Suppl 1):80-4.

12)Bergendal T, Engquist B. Implant-supported overdentures: a longitudinal prospective study. Int $\mathrm{J}$ Oral Maxillofac Implants. 1998;13:253-62.

13) Kenney R, Richards MW. Photoelastic stress patterns produced by implant-retained overdentures. J Prosthet Dent.1998;80:559-6.

14)Chikunov I, Doan P, Vahidi F. Implant-retained partial overdenture with resilient attachments. J Prosthodont. 2008; 17:141-8.

15)Mazor Z, Lorean A, Mijiritsky E, Levin L. Nasal floor elevation combined with dental implant placement. Clin Implant Dent Relat Res. 2012;14:768-71.

16)El-Ghareeb M, Pi-Anfruns J, Khosousi M, Aghaloo T, Moy P. Nasal floor augmentation for the reconstruction of the atrophic maxilla: a case series. J Oral Maxillofac Surg. 2012;70:e235-41.

17) Ammar NA. Clinical evaluation of the implant retained over denture with two-equator attachments. M.S.c. Thesis. Department of Removable Prothodontics, Faculty of Dentistry, Alexandria University. Egypt; 2016.

18)Inglehart $M$, Bagramian R. Oral health related quality of life: an introduction. In: Inglehart M, Bagramian R (eds). Oral health related quality of life. Chicago: Quintessence; 2002. 1-6.

19)Papaspyridakos P, Chen CJ, Singh M, Weber HP, Gallucci GO. Success criteria in implant dentistry: a systematic review. J Dent Res. 2012;91:242-8. 
20) Khairnar M, Gaur V. Evidence of bone formation in the nasal floor around polished surface bi-cortical screw implants after indirect nasal lift in an atrophied maxilla: Cone beam computed tomography-based case report. J Indian Soc Periodontol. 2015;19:236-8.

21)Choukroun J, Diss A, Simonpieri A, Girard MO, Schoeffler C, Dohan SL et al. Platelet-rich fibrin (PRF): a secondgeneration platelet concentrate. Part IV: clinical effects on tissue healing. Oral Surg Oral Med Oral Pathol Oral Radiol Endod. 2006;101:e56-60.

22) Ozan O, Ramolgu S. Effect of implant height differences on different attachment types and peri-implant bone in mandibular two-implant overdentures: 3D finite element study. J Oral Implantol. 2015:41:e50-9.

23)Ibrahim AM. Evaluation of low-profile attachments for implant-retained mandibular overdentures in restoring cases with limited inter-arch space. CDJ .2009;25:191-203.

24)Griffiths GR. Bone density around endosseous implants in patients taking alendronate: a pilot study. Int J Periodontics Restorative Dent. 2012;32:e101-8.

25) Sykaras N, Iacopino AM, Marker VA, Triplett RG, Woody RD. Implant materials, designs, and surface topographies: their effect on osseointegration. A literature review. Int J Oral Maxillofac Implants. 2000;15:675-90.

26)Rismanchian M, Bajoghli F, Eblaghian G, Reihany A, Yousefshahi H. Stress analysis of ball and locator attachments and bone in overdenture supported by tissue level and bone level implants: a three-dimensional finite element analysis. J Int Oral Health. 2016;8:952-7.

27)Rubin CT, Mcleod KJ. Promotion of bony ingrowth by frequency-specific, low amplitude mechanical strain. Clin Orthop Relat Res. 1994;298:165-74.

28)Dos Santos MB, Da Silva Neto JP, Consani RL, Mesquita MF. Three dimensional finite element analysis of stress distribution in peri-implant bone with relineddentures and different heights of healing caps. J Oral Rehabil. 2011; 38:691-6.

29) Kronstrom M, Widbom C, Soderfeldt B. Patient evaluation after treatment with maxillaryimplant-supported overdentures. Clin Implant Dent Relat Res. 2006;8:39-43.

30) Kapur KK, Garrett NR, Hamada MO, Roumanas ED, Freymiller E, Han $\mathrm{T}$, et al. A randomized clinical trial comparing the efficacy of mandibular implant-supported overdentures and conventional dentures in diabetic patients. Part I: Methodology and clinical outcomes. J Prosthet Dent. 1998;79:555-69.

31) Naert I, Quirynen M, Theuniers G, van Steenberghe D. Prosthetic aspects of osseointegrated fixtures supporting overdentures. A 4-year report. J Prosthet Dent. 1991;65:671-80.

32) Grossmann Y, Levin L. Success and survival of single dental implants placed in sites of previously failed implants. J Periodontol. 2007;78:1670-4. 